\title{
Habilidade competitiva relativa de milhã em convivência com arroz irrigado e soja
}

\author{
Dirceu Agostinetto(1), Lisiane Camponogara Fontana(1), \\ Leandro Vargas ${ }^{(2)}$, Catarina Markus ${ }^{(1)}$ e Ezequiel de Oliveira ${ }^{(1)}$ \\ (1) Universidade Federal de Pelotas, Faculdade de Agronomia Eliseu Maciel, Departamento de Fitossanidade, Campus \\ Universitário, Caixa Postal 354, CEP 96010-900 Pelotas, RS. E-mail: dirceu.agostinetto@pq.cnpq.br, lisicamponogara@gmail.com, \\ catarine.markus@gmail.com, oliveira.agro@gmail.com ${ }^{(2)}$ Embrapa Trigo, BR-285, Km 174, Caixa Postal 451, CEP 99001-970 Passo Fundo, RS. \\ E-mail: leandro.vargas@embrapa.br
}

Resumo - O objetivo deste trabalho foi comparar a habilidade competitiva relativa de milhã com as culturas de arroz irrigado e de soja. Realizaram-se cinco experimentos, nas safras de 2009/2010 e 2010/2011, em delineamento inteiramente casualizado, com quatro repetições. Os tratamentos consistiram de proporções de plantas de milhã e arroz irrigado ou soja (100:0, 75:25, 50:50, 25:75 e 0:100\%). A área foliar e a massa de matéria seca da parte aérea foram avaliadas aos 45 dias após a emergência. A competição entre milhã e arroz irrigado ou soja ocorre pelos mesmos recursos do ambiente. Plantas de milhã apresentam menor habilidade competitiva por indivíduo do que o arroz irrigado e a soja, quando ocorrem na mesma proporção de plantas. Quando as culturas do arroz irrigado ou da soja estão associadas ao milhã, a competição intraespecífica predomina, enquanto, para a planta daninha, prevalece a competição interespecífica como a mais prejudicial.

Termos para indexação: Digitaria ciliaris, Glycine max, Oryza sativa, interferência.

\section{Relative competitive ability of crabgrass in coexistence with flooded rice and soybean}

\begin{abstract}
The objective of this work was to compare the relative competitive ability of crabgrass with flooded rice and soybean crops. Five experiments were performed in the 2009/2010 and 2010/2011 seasons, in a completely randomized design with four replicates. The treatments consisted of plant proportions of crabgrass, flooded rice or soybean (at 100:0, 75:25, 50:50, 25:75 and 0:100\%). Leaf area and shoot dry weight were evaluated at 45 days after emergence. The competition between crabgrass and flooded rice or soybean occurs for the same environment resources. Crabgrass plants have a lower individual competitive ability than flooded rice and soybean, when they occur in the same proportion of plants. When flooded rice or soybean are associated with crabgrass, the intraspecific competition dominates, while for the weed the interspecific competition prevails as the most harmful.
\end{abstract}

Index terms: Digitaria ciliaris, Glycine max, Oryza sativa, interference.

\section{Introdução}

As culturas do arroz irrigado e da soja destacam-se entre os cultivos agrícolas do país, e a competição com plantas daninhas é um dos principais fatores limitantes à produtividade. A competição de plantas daninhas reduz a produtividade do arroz irrigado, conforme relatado sobre o capim-arroz (Echinochloa spp.) (Galon et al., 2007) e o arroz-vermelho (Oryza sativa) (Agostinetto et al., 2004). Na cultura da soja, as interferências de apaga-fogo (Alternanthera tenella), capim-amoroso (Cenchrus echinatus) (Nepomuceno et al., 2007), picão-preto (B. pilosa e B. subalternans) (Rizzardi et al., 2003; Nepomuceno et al., 2007) e nabo forrageiro (Raphanus sativus) (Fleck et al., 2006) também causaram reduções de produtividade.

A competição pode ser intraespecífica, quando ocorre entre indivíduos da mesma espécie, ou interespecífica, quando se dá entre espécies diferentes, e é possível quantifica-la por meio de estudos em séries substitutivas (Roush et al., 1989). Estudos desenvolvidos com esta metodologia mostraram que o arroz-vermelho e o capim-arroz têm maior habilidade competitiva, do que o arroz irrigado (Agostinetto et al., 2008; Fleck et al., 2008). No entanto o junquinho (Cyperus difformis) e o cuminho (Fimbristylis miliacea) são menos competitivos do que o arroz irrigado (Dal Magro et al., 2011; Schaedler, 2011). Para 
soja e papuã (Urochloa plantaginea. syn. Brachiaria plantaginea), ocorreu antagonismo no crescimento das espécies em associação, o que mostra que a competição intraespecífica foi mais importante do que a competição interespecífica (Rigoli et al., 2008), diferentemente do nabo forrageiro, que exerce maior interferência sobre a cultura da soja (Bianchi et al., 2006). Em associações de soja com leiteira (Euphorbia heterophylla) e corda-de-viola (Ipomoea ramosissima), a redução da matéria seca da cultura foi mais intensa em presença da corda-de-viola e, principalmente, em situações em que a planta daninha se estabeleceu antes da soja (Rizzardi et al., 2004). Assim, a maior competitividade da cultura ou da planta daninha pode estar relacionada à maior capacidade de apreensão dos recursos do meio, menor necessidade do recurso ou emergência antecipada em relação à outra espécie e população presente. Para a espécie milhã, em competição com arroz irrigado ou soja, não foram observados trabalhos, na literatura, que tenham quantificado esta interferência.

O objetivo deste trabalho foi comparar a habilidade competitiva relativa de milhã (Digitaria ciliaris) com as culturas de arroz irrigado ou de soja.

\section{Material e Métodos}

Foram realizados experimentos em casa de vegetação, na Faculdade de Agronomia Eliseu Maciel (Faem), da Universidade Federal de Pelotas (UFPel), nas safras agrícolas de 2009/2010 e 2010/2011.

A população de plantas, a ser utilizada nos experimentos, foi determinada em experimento prévio conduzido em série aditiva. $O$ valor da massa de matéria seca da parte aérea (MMSPA) (g) foi estabelecido por unidade de área $\left(\mathrm{m}^{2}\right)$, independente da população, conforme a lei de produção final constante (Radosevich et al., 2007), a qual indica a capacidade de suporte do ambiente, ou seja, a produção final fica limitada à capacidade do ambiente; assim, o aumento populacional não importa, pois, a produção final de MMSPA será constante. Para isso, monocultivos de arroz irrigado, soja e milhã foram estabelecidos em condição de alagamento e de sequeiro, respectivamente, em que as populações foram 1, 2, 4, 8, 16, 32, 64 e 128 plantas por vaso (equivalentes a $37,74,148$, 296, 592, 1.184, 2.368 e 4.736 plantas $\mathrm{m}^{-2}$ ), no total de 32 vasos. Coletou-se a parte aérea das plantas aos 45 dias após a emergência (DAE), para determinar a
MMSPA, que foi quantificada pela pesagem da parte aérea das plantas após serem secas em estufa com circulação forçada de ar a $60^{\circ} \mathrm{C}$ por 72 horas. Por meio do valor médio de MMSPA das espécies, obtiveramse produções constantes de MMSPA, com população de 24 plantas por vaso, de arroz irrigado e milhã, em condição alagada, e 12 plantas por vaso de soja e milhã, em sequeiro.

Para a avaliação da habilidade competitiva da milhã, foram realizados quatro experimentos em série substitutiva, dos quais dois com milhã associada ao arroz irrigado e dois com milhã associada à soja. Utilizou-se o método de série de substituição em que a produtividade das associações de espécies foi determinada em relação ao monocultivo. A série de substituição é feita com a cultura sozinha ou em associação com plantas daninhas, em que as proporções de indivíduos das duas espécies estudadas variam, mas a população total de plantas é mantida constante.

Em todos os experimentos, utilizou-se o delineamento inteiramente casualizado, com quatro repetições. As unidades experimentais constituíramse de vasos preenchidos com solo, com capacidade volumétrica de $8 \mathrm{~L}$ e diâmetro da superfície de $23 \mathrm{~cm}$. A adubação foi realizada conforme a análise de solo e as recomendações técnicas para as culturas (Congresso Brasileiro de Arroz Irrigado \& Reunião da Cultura do Arroz Irrigado, 2007; Reunião de Pesquisa da Soja da Região Sul, 2008). Utilizaramse as seguintes cultivares: 'BRS Querência', de arroz irrigado; 'Fundacep 53 RR' de soja; e dois biótipos de Digitaria ciliaris, encontrados em áreas agrícolas de várzea e sequeiro, provenientes dos municípios de Santa Vitória do Palmar $\left(32^{\circ} 54^{\prime} 5^{\prime \prime} S\right.$ e $\left.52^{\circ} 43^{\prime} 32^{\prime \prime} W\right)$ e Pelotas (31 $28^{\circ} 50^{\prime \prime} \mathrm{S}$ e $\left.52^{\circ} 18^{\prime} 5^{\prime \prime} \mathrm{W}\right)$, respectivamente. A irrigação para os experimentos com arroz irrigado foi feita por inundação, a partir dos 15 dias após a emergência, enquanto para soja foi realizada irrigação diária.

Os tratamentos consistiram de proporções de plantas de milhã e arroz irrigado ou soja, no total de 40 vasos para cada safra. As proporções testadas foram: 100:0 (estande só com milhã), 75:25, 50:50, 25:75 e 0:100\% (estande só com arroz irrigado ou soja). Para estabelecer as populações, semearam-se as espécies em densidades superiores às desejadas, com posterior retirada das plantas excedentes, tendo-se estabelecido a população determinada no primeiro experimento. 
Aos 45 DAE, avaliaram-se as variáveis área foliar (AF) e MMSPA. Determinou-se a AF ( $\mathrm{cm}^{2}$ por planta) com auxílio de medidor de área foliar LI 3100C (LI-COR, Lincoln, USA). A MMSPA (g por planta) foi quantificada conforme descrito anteriormente.

Para a análise dos dados referentes às variáveis AF e MMSPA do competidor (Digitaria ciliaris) e da cultura (arroz irrigado ou soja), utilizou-se o método de análise gráfica da produtividade relativa (Radosevich, 1987; Roush et al., 1989; Cousens, 1991). Esse procedimento consiste na construção de diagramas, com base na produtividade relativa $(\mathrm{PR})$ e produtividade relativa total (PRT) das plantas do competidor e da cultura. Nesses diagramas, os resultados obtidos são comparados aos valores de uma reta hipotética que une os pontos zero e 100, o que representa a ausência de interferência de um genótipo sobre outro. A PR que resulta em linha côncava indica que ocorreu prejuízo no crescimento de uma ou de ambas as espécies e, PR com linha convexa indica que houve benefício no crescimento de uma ou de ambas as espécies. A PRT é representada pela soma das produtividades relativas do competidor e da cultura, nas respectivas proporções de plantas. A PRT igual à unidade (linha reta) indica que ocorre competição pelo(s) mesmo(s) recurso(s); PRT superior a um (linha convexa) indica que não ocorre competição; quando inferior a um (linha côncava), a PRT indica que ocorre antagonismo, e, portanto, que há prejuízo mútuo ao crescimento das espécies.

Calcularam-se índices de competitividade relativa (CR), coeficientes de agrupamento relativo $(\mathrm{K})$ e de competitividade (C), para a proporção de plantas 50:50, tendo-se utilizado as equações propostas por Cousens \& O’Neill (1993). A CR representa o crescimento comparativo da milhã $(\mathrm{M})$ em relação à cultura $(\mathrm{C})$; $\mathrm{K}$ indica a dominância relativa de uma espécie sobre a outra; e $\mathrm{C}$ aponta qual espécie se manifesta como mais competitiva (Cousens, 1991). A cultura é mais competitiva que a milhã, quando $\mathrm{CR}>1, \mathrm{~K}_{\mathrm{C}}>\mathrm{K}_{\mathrm{M}}\left(\mathrm{K}_{\mathrm{C}}\right.$, dominância relativa da cultura; e $\mathrm{K}_{\mathrm{M}}$, dominância relativa da milhã) e $\mathrm{C}>0$; e, a milhã é mais competitiva que a cultura, quando $\mathrm{CR}<1, \mathrm{~K}_{\mathrm{C}}<\mathrm{K}_{\mathrm{M}}$ e $\mathrm{C}<0$ (Hoffman \& Buhler, 2002). A interpretação conjunta desses valores indica com maior segurança a competitividade das espécies envolvidas.

Para analisar estatisticamente a produtividade relativa, primeiramente, calculou-se a diferença para os valores de PR ou diferenças relativas de produtividade (DPR), obtidos às proporções de 25,50 e $75 \%$ de plantas, em relação aos valores pertencentes às retas hipotéticas obtidas nas respectivas proporções. Em seguida, realizou-se o teste $\mathrm{t}(\mathrm{p} \leq 0,05)$, para testar as diferenças nos índices DPR, PRT, CR, K e C (Roush et al., 1989; Hoffman \& Buhler, 2002). O critério para considerar as curvas de PR e PRT diferentes das retas hipotéticas ou se haveria diferença em competitividade (CR, K e C), foi que, no mínimo, em duas proporções, ocorressem diferenças significativas pelo teste $\mathrm{t}$ (Bianchi et al., 2006).

Os resultados obtidos para AF e MMSPA das plantas, expressos em valores médios por planta, foram também submetidos à análise de variância. Quando o teste $\mathrm{F}$ indicou significância $(p \leq 0,05)$, compararam-se as médias dos tratamentos pelo teste de Dunnett $(p \leq 0,05)$, tendo-se considerado as respectivas monoculturas como testemunhas.

\section{Resultados e Discussão}

A interpretação da análise de variância dos dados mostrou que há, em geral, interações significativas entre as proporções de plantas de milhã e arroz irrigado ou soja.

A PRT não diferiu significativamente de 1 (linha reta), em todas as variáveis avaliadas na cultura do arroz nas duas safras, o que indica que a competição entre arroz irrigado e milhã ocorreu pelos mesmos recursos do meio (Figura 1, Tabela 1).

As espécies diferiram na resposta à condição de competição estabelecida. Para as variáveis AF e MMSPA, nos dois anos, a PR da cultura do arroz resultou em linha convexa e a da milhã em linha côncava, indicando benefício para a cultura e prejuízo para a planta daninha (Figura 1). Assim, o arroz irrigado foi mais competitivo do que a milhã, tendo utilizado mais eficientemente os recursos e contribuído mais do que o esperado para a PRT (Dal Magro et al., 2011; Schaedler, 2011).

As diferenças de PR (DPR) do arroz irrigado e da milhã, em relação às respectivas retas hipotéticas, foram significativas em pelo menos duas proporções de plantas, o que confirma os resultados observados na análise gráfica (Tabela 1). Embora a cultura apresente maior habilidade competitiva, os danos ocasionados pelas plantas daninhas ocorrem, pois se relacionaram à maior população (Vilá et al, 2004; Carvalho \& Christoffoleti,

Pesq. agropec. bras., Brasília, v.48, n.10, p.1315-1322, out. 2013 DOI: 10.1590/S0100-204X2013001000002 
2008). Nas áreas agrícolas, as plantas daninhas ocorrem, normalmente, em populações superiores às das plantas cultivadas e, frequentemente, são consideradas como mais competitivas na apreensão e utilização dos recursos quando, na realidade, o efeito decorre da maior população de plantas (Bianchi et al., 2006).

O crescimento do arroz superou o da milhã, conforme indicado pelo índice CR (superior a 1) para AF e MMSPA (Tabela 2). Além disso, observou-se dominância relativa do arroz irrigado sobre a milhã, pelo índice $\mathrm{K}$, e que a cultura é mais competitiva do que a planta daninha pelo índice C. A interpretação destes índices corrobora o observado na análise gráfica e assegura que houve dominância da cultura do arroz em relação à planta daninha milhã. Observaram-se resultados semelhantes em arroz irrigado em competição com junquinho (Dal Magro et al., 2011). Em geral, a cultura é mais competitiva do que a espécie daninha, em termos individuais, porque o efeito das
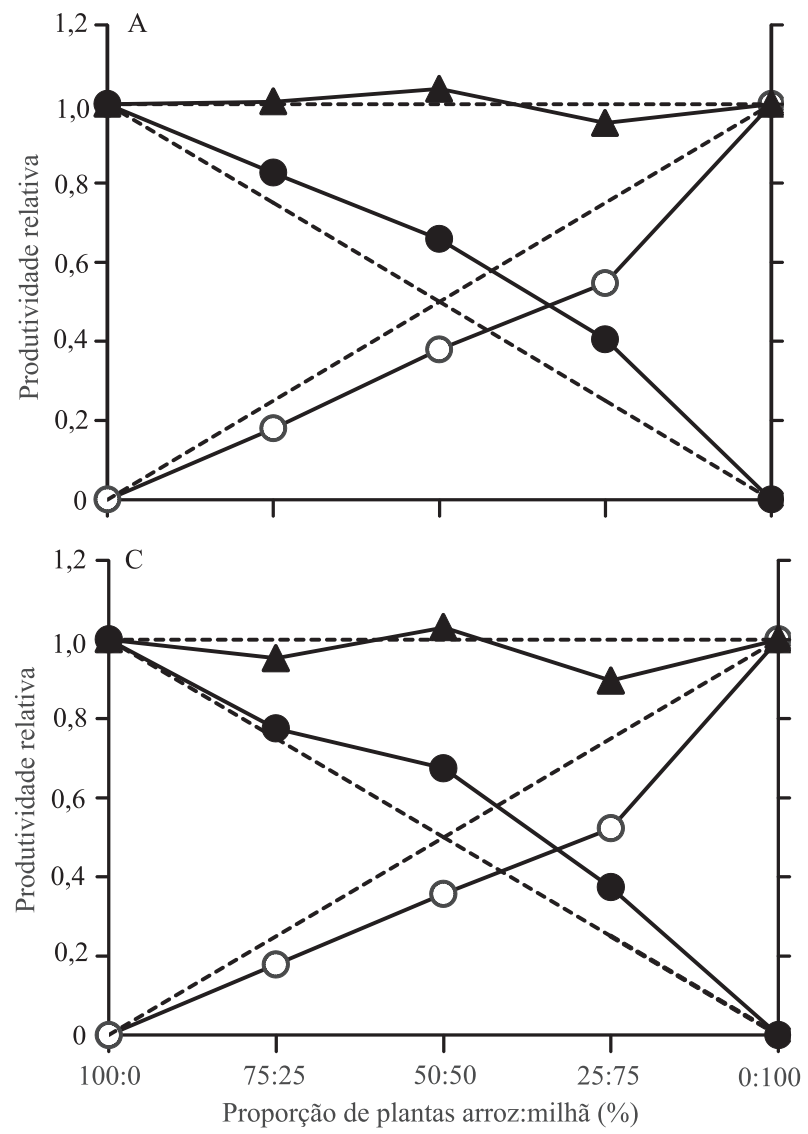

plantas daninhas não se deve à sua maior habilidade competitiva individual, mas, principalmente, pelo efeito combinado de sua população total de plantas (Vilá et al., 2004). No entanto, em alguns casos, a planta daninha apresentou maior habilidade competitiva do que o arroz irrigado, conforme observado em capim-arroz (Agostinetto et al., 2008) e nas espécies de arroz-vermelho Oryza sativa (Fleck et al., 2008) e O. punctata (Munene et al., 2008). A maior competitividade de uma espécie indica que ela terá maior capacidade de assimilação dos recursos do nicho ecológico e, assim, maior potencial de crescimento e desenvolvimento, o que acarreta o aumento do dano ao competidor, pois, menores quantidades de recursos ficarão disponíveis.

Comparando-se os valores de AF e MMSPA do arroz, em cada proporção da mistura $(25,50$ e $75 \%)$, com os obtidos na monocultura (100\%), constatou-se que a competição intraespecífica em arroz foi expressiva,
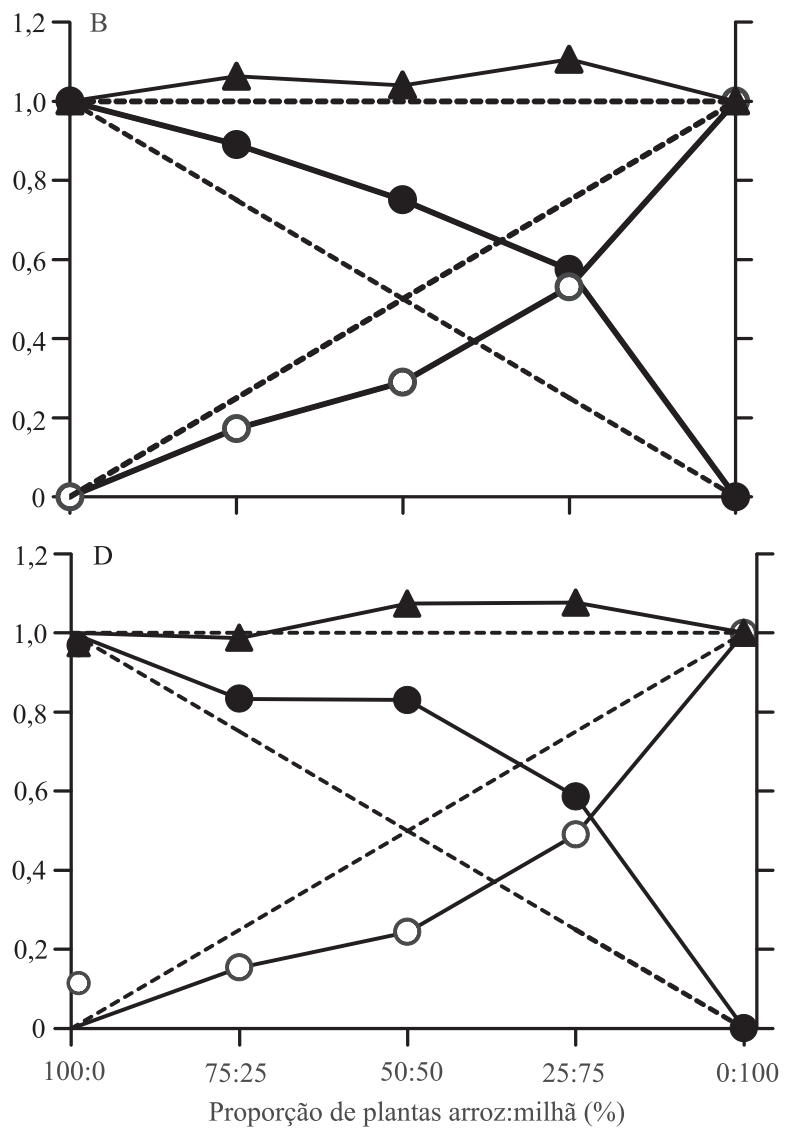

Figura 1. Produtividade relativa de arroz irrigado $(\bullet)$ e de milhã (Digitaria ciliaris)(○) e produtividade relativa total ( $\mathbf{\nabla})$, quanto à área foliar (A e B, para 2009/2010 e 2010/2011, respectivamente) e massa de matéria seca da parte aérea (C e D, para 2009/2010 e 2010/2011, respectivamente), em função das proporções entre as espécies. As linhas tracejadas referem-se à produtividade relativa hipotética, quando não ocorre interferência de uma espécie sobre a outra. 
pois se obtiveram as maiores médias por planta da cultura, quando esta se apresentava em população menor do que a do competidor (Tabela 3). Assim, a competição interespecífica foi menos prejudicial do que a intraespecífica. Para milhã, a competição interespecífica foi mais importante, visto que $\mathrm{AF}$ e MMSPA por planta foram maiores no monocultivo (100\% milhã).

De acordo com Woldeamlak et al. (2001), as culturas semeadas em associação com espécies daninhas, com variação na proporção de plantas, normalmente apresentam vantagem quanto à produtividade relativa, o que mostra que a competição intraespecífica excede a interespecífica. Resultados semelhantes ocorreram na cultura do trigo, em convivência com azevém (Rigoli et al., 2008) e arroz irrigado em competição com junquinho (Dal Magro et al., 2011), diferentemente das relações de interferência entre arroz e arroz-vermelho (Fleck et al., 2008) ou capim-arroz (Agostinetto et al., 2008), que resultaram em vantagem para as espécies daninhas.

A cultura da soja foi mais competitiva do que a de milhã, nas duas safras, em ambas as variáveis avaliadas, e a PR de soja foi representada por linha convexa e a de milhã por linha côncava (Figura 2). De modo semelhante ao verificado para a interação de arroz irrigado e milhã, a competição entre as duas espécies ocorreu, basicamente, pelos mesmos recursos do meio; no entanto, estes foram utilizados mais eficientemente pela cultura (Dal Magro et al., 2011; Schaedler, 2011). Em geral, os DPR de soja e de milhã, ao serem comparados com as respectivas

Tabela 1. Diferenças relativas de produtividade (DPR) e produtividade relativa total (PRT), nas proporções de plantas de arroz irrigado ou soja associadas com milhã (Digitaria ciliaris).

\begin{tabular}{|c|c|c|c|c|c|c|}
\hline \multirow[t]{2}{*}{ Característica } & \multicolumn{3}{|c|}{ Proporções de plantas de arroz irrigado : milhã } & \multicolumn{3}{|c|}{ Proporções de plantas de soja : milhã } \\
\hline & $75: 25$ & $50: 50$ & $25: 75$ & $75: 25$ & $50: 50$ & $25: 75$ \\
\hline & \multicolumn{6}{|c|}{ Safra 2009/2010 - Área foliar } \\
\hline DPR arroz/soja & $0,08 \pm 0,05^{\mathrm{ns}}$ & $0,16 \pm 0,02 *$ & $0,15 \pm 0,01 *$ & $0,17 \pm 0,01 *$ & $0,10 \pm 0,02 *$ & $0,21 \pm 0,05 *$ \\
\hline DPR milhã & $-0,07 \pm 0,01 *$ & $-0,12 \pm 0,01 *$ & $-0,20 \pm 0,03 *$ & $-0,23 \pm 0,00 *$ & $-0,40 \pm 0,01 *$ & $-0,46 \pm 0,10 *$ \\
\hline \multirow[t]{2}{*}{ PRT } & $1,01 \pm 0,05^{\mathrm{ns}}$ & $1,04 \pm 0,02^{\mathrm{ns}}$ & $0,95 \pm 0,03^{\mathrm{ns}}$ & $0,94 \pm 0,01 *$ & $0,70 \pm 0,01 *$ & $0,74 \pm 0,06^{*}$ \\
\hline & \multicolumn{6}{|c|}{ Safra 2010/2011 - Área foliar } \\
\hline DPR arroz/soja & $0,14 \pm 0,04 *$ & $0,25 \pm 0,01 *$ & $0,32 \pm 0,02 *$ & $0,11 \pm 0,05^{\mathrm{ns}}$ & $0,14 \pm 0,03 *$ & $0,15 \pm 0,03 *$ \\
\hline DPR milhã & $-0,08 \pm 0,01^{*}$ & $-0,21 \pm 0,04 *$ & $-0,22 \pm 0,05^{*}$ & $-0,07 \pm 0,01^{*}$ & $-0,24 \pm 0,01 *$ & $-0,27 \pm 0,01 *$ \\
\hline \multirow[t]{2}{*}{ PRT } & $1,06 \pm 0,03^{\mathrm{ns}}$ & $1,04 \pm 0,05^{\mathrm{ns}}$ & $1,11 \pm 0,05^{\mathrm{ns}}$ & $1,04 \pm 0,05^{\mathrm{ns}}$ & $0,90 \pm 0,02 *$ & $0,88 \pm 0,02 *$ \\
\hline & \multicolumn{6}{|c|}{ Safra 2009/2010 - Massa de matéria seca da parte aérea } \\
\hline DPR arroz/soja & $0,02 \pm 0,02^{\mathrm{ns}}$ & $0,17 \pm 0,01 *$ & $0,12 \pm 0,02 *$ & $0,17 \pm 0,01 *$ & $0,11 \pm 0,01 *$ & $0,20 \pm 0,04 *$ \\
\hline DPR milhã & $-0,07 \pm 0,03^{\mathrm{ns}}$ & $-0,14 \pm 0,01 *$ & $-0,23 \pm 0,01 *$ & $-0,24 \pm 0,01 *$ & $-0,42 \pm 0,01 *$ & $-0,41 \pm 0,05^{*}$ \\
\hline \multirow[t]{2}{*}{ PRT } & $0,95 \pm 0,03^{\mathrm{ns}}$ & $1,03 \pm 0,01^{\mathrm{ns}}$ & $0,90 \pm 0,04^{\mathrm{ns}}$ & $0,93 \pm 0,01 *$ & $0,69 \pm 0,01 *$ & $0,79 \pm 0,01 *$ \\
\hline & \multicolumn{6}{|c|}{ Safra 2010/2011 - Massa de matéria seca da parte aérea } \\
\hline DPR arroz/soja & $0,08 \pm 0,04^{\mathrm{ns}}$ & $0,33 \pm 0,02 *$ & $0,34 \pm 0,01 *$ & $0,09 \pm 0,02^{\mathrm{ns}}$ & $0,17 \pm 0,04^{\mathrm{ns}}$ & $0,16 \pm 0,03 *$ \\
\hline DPR milhã & $-0,10 \pm 0,01^{*}$ & $-0,26 \pm 0,02 *$ & $-0,26 \pm 0,05^{*}$ & $-0,11 \pm 0,01^{*}$ & $-0,32 \pm 0,01 *$ & $-0,34 \pm 0,03 *$ \\
\hline PRT & $0,99 \pm 0,04^{\mathrm{ns}}$ & $1,07 \pm 0,04^{\mathrm{ns}}$ & $1,08 \pm 0,06^{\mathrm{ns}}$ & $0,98 \pm 0,03 \mathrm{~ns}$ & $0,85 \pm 0,04^{*}$ & $0,82 \pm 0,05^{*}$ \\
\hline
\end{tabular}

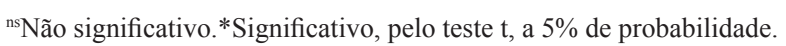

Tabela 2. Índices de competitividade entre arroz irrigado ou soja e milhã (Digitaria ciliaris), expressos por competitividade relativa (CR) e coeficientes de agrupamento relativo (K) e de competitividade (C).

\begin{tabular}{|c|c|c|c|c|c|c|c|c|}
\hline \multirow[t]{2}{*}{ Característica } & \multicolumn{4}{|c|}{ Arroz irrigado : milhã } & \multicolumn{4}{|c|}{ Soja : milhã } \\
\hline & $\mathrm{CR}$ & $\mathrm{K}$ arroz & K milhã & $\mathrm{C}$ & $\mathrm{CR}$ & $\mathrm{K}$ arroz & K milhã & $\mathrm{C}$ \\
\hline \multicolumn{9}{|c|}{ Safra 2009/2010 } \\
\hline Área foliar & $1,74 \pm 0,06^{*}$ & $1,94 \pm 0,15^{*}$ & $0,61 \pm 0,01$ & $0,28 \pm 0,02 *$ & $6,39 \pm 0,76^{*}$ & $1,51 \pm 0,12^{*}$ & $0,10 \pm 0,01$ & $0,50 \pm 0,03 *$ \\
\hline MMSPA & $1,90 \pm 0,11 *$ & $2,08 \pm 0,13 *$ & $0,55 \pm 0,03$ & $0,32 \pm 0,03 *$ & $8,19 \pm 0,96^{*}$ & $1,58 \pm 0,08^{*}$ & $0,08 \pm 0,01$ & $0,53 \pm 0,02 *$ \\
\hline \multicolumn{9}{|c|}{ Safra 2010/2011 } \\
\hline Área foliar & $2,69 \pm 0,36^{*}$ & $3,03 \pm 0,24 *$ & $0,41 \pm 0,08$ & $0,46 \pm 0,04 *$ & $1,97 \pm 0,23^{\mathrm{ns}}$ & $1,87 \pm 0,37^{\mathrm{ns}}$ & $0,49 \pm 0,03$ & $0,31 \pm 0,06^{*}$ \\
\hline MMSPA & $3,47 \pm 0,30^{*}$ & $5,01 \pm 0,56^{*}$ & $0,32 \pm 0,04$ & $0,59 \pm 0,01 *$ & $3,68 \pm 0,30^{*}$ & $2,13 \pm 0,38^{*}$ & $0,22 \pm 0,02$ & $0,48 \pm 0,04 *$ \\
\hline
\end{tabular}

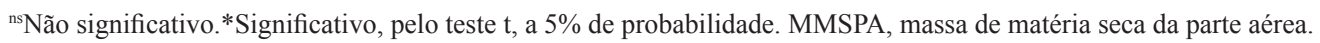


retas hipotéticas, foram significativos (Tabela 1), o que confirma os resultados observados na análise gráfica. Observaram-se resultados semelhantes, na cultura do feijão, por Carvalho \& Christoffoleti (2008), o que sugere que os danos causados pelas plantas daninhas relacionaram-se mais estreitamente com as altas populações de ocorrência do que com a habilidade competitiva intrínseca das espécies.

As PRT de AF e MMSPA apresentaram diferenças significativas e foram inferiores a 1 , que corresponde a linhas côncavas e mostra que a competição entre a cultura da soja e a milhã ocorreu pelos mesmos recursos do meio (Radosevich, 1987; Roush et al., 1989; Cousens, 1991). No entanto, não houve prejuízo mútuo ao crescimento das espécies, pois a PR da soja foi representada por linha convexa, enquanto a PR da milhã foi por uma linha côncava. Isto indica que a redução da produção total decorreu da menor contribuição da planta daninha, ocasionada pela maior competitividade da soja e não propriamente pela ocorrência de prejuízo mútuo entre as espécies. De acordo com Jannink et al. (2000), as culturas podem responder à competição reduzindo o crescimento das plantas daninhas por efeito de interferência.

A competitividade relativa da soja, indicada pelo índice CR, superou o da milhã, o que representa a dominância da cultura sobre a competidora, conforme indicado também pelos índices $\mathrm{K}$ e $\mathrm{C}$, em todas as variáveis avaliadas, e mostra a vantagem competitiva da cultura (Tabela 2). Verificaram-se resultados semelhantes para a cultura do feijão em competição com papuã (Passini et al., 2003) ou com diferentes espécies de caruru (Amaranthus deflexus, A. hybridus, A. retroflexus, A. spinosus e $A$. viridis) (Carvalho \& Christoffoleti, 2008). No entanto, a planta daninha pode mostrar-se mais competitiva do que a cultura, conforme foi observado em nabo forrageiro, em competição com soja (Bianchi et al., 2006). Pode, ainda, ocorrer prejuízo ao crescimento de ambas as espécies, conforme observado entre soja e papuã (Agostinetto et al., 2009), ou não ocorrer competição, conforme verificado em associações de soja com leiteira ou corda-de-viola (Rizzardi et al., 2004).

Comparando-se a AF produzida e o acúmulo de MMSPA para cada proporção da associação $(25,50$ e $75 \%$ ), com as obtidas na respectiva monocultura $(100 \%)$, constatou-se que a competição intraespecífica para a soja foi mais severa, enquanto para milhã a competição interespecífica foi mais importante (Tabela 3). Constataram-se as maiores médias de AF e MMSPA por planta de soja, quando esta se encontrava em menor proporção na mistura ( $25 \%$ de soja). Para milhã, quanto maior foi sua proporção na mistura, maior a produção de AF e MMSPA por planta, pois, em todas as proporções de milhã com soja, a produção destas variáveis diminuiu em relação ao monocultivo de milhã. Resultados semelhantes evidenciaram que, para a cultura do feijão, houve competição intraespecífica e mínima competição interespecífica com papuã (Passini et al., 2003). Neste caso, o efeito da cultura sobre a planta daninha foi maior do que o efeito competitivo entre as plantas de papuã.

Tabela 3. Resposta do arroz irrigado ou soja à interferência de milhã (Digitaria ciliaris), aos 45 dias após a emergência.

\begin{tabular}{|c|c|c|c|c|c|c|c|c|c|c|c|c|}
\hline \multirow[t]{2}{*}{ Cultura } & \multicolumn{5}{|c|}{ Proporções de plantas de arroz irrigado : milhã } & \multirow{2}{*}{$\begin{array}{l}\text { CV } \\
(\%)\end{array}$} & \multicolumn{5}{|c|}{ Proporções de plantas de soja : milhã } & \multirow{2}{*}{$\begin{array}{l}\text { CV } \\
(\%)\end{array}$} \\
\hline & $100: 0(\mathrm{~T})$ & $75: 25$ & $50: 50$ & $25: 75$ & $0: 100(\mathrm{~T})$ & & $100: 0(\mathrm{~T})$ & $75: 25$ & $50: 50$ & $25: 75$ & $0: 100(\mathrm{~T})$ & \\
\hline & \multicolumn{12}{|c|}{ Safra $2009 / 2010$ - Área foliar $\left(\mathrm{cm}^{2}\right.$ por planta $)$} \\
\hline Arroz/soja & 41,77 & 46,02 & $55,00^{*}$ & $67,66^{*}$ & - & 5,31 & 143,35 & 175,93 & 172,06 & $262,54 *$ & - & 11,83 \\
\hline \multirow[t]{2}{*}{ Milhã } & - & $16,79 *$ & $17,75^{*}$ & $17,05^{*}$ & 23,38 & 11,45 & - & $4,76^{*}$ & $14,03 *$ & $27,86^{*}$ & 73,32 & 27,17 \\
\hline & \multicolumn{12}{|c|}{ Safra 2010/2011 - Área foliar $\left(\mathrm{cm}^{2}\right.$ por planta $)$} \\
\hline Arroz/soja & 121,34 & $144,08^{*}$ & $182,04 *$ & $278,80^{*}$ & - & 5,42 & 120,89 & 139,18 & 154,92 & $195,13 *$ & - & 12,66 \\
\hline \multirow[t]{2}{*}{ Milhã } & - & $31,82 *$ & $26,75^{*}$ & $32,66^{*}$ & 46,15 & 14,73 & - & $55,81^{*}$ & $49,10^{*}$ & $49,18^{*}$ & 74,47 & 9,31 \\
\hline & \multicolumn{12}{|c|}{ Safra 2009/2010 - Massa de matéria seca da parte aérea (g por planta) } \\
\hline Arroz/soja & 0,42 & 0,44 & $0,57^{*}$ & $0,63 *$ & - & 7,66 & 1,29 & 1,58 & 1,58 & $2,22 *$ & - & 10,26 \\
\hline \multirow[t]{2}{*}{ Milhã } & - & $0,18 *$ & $0,18 *$ & $0,19 *$ & 0,26 & 15,06 & - & $0,02 *$ & $0,09 *$ & $0,25^{*}$ & 0,56 & 13,72 \\
\hline & \multicolumn{12}{|c|}{ Safra 2010/2011 - Massa de matéria seca da parte aérea (g por planta) } \\
\hline Arroz/soja & 1,24 & 1,37 & $2,05^{*}$ & $2,90 *$ & - & 4,57 & 1,39 & 1,54 & $1,86^{*}$ & $2,26^{*}$ & - & 11,39 \\
\hline Milhã & - & $0,29 *$ & $0,23 *$ & $0,31 *$ & 0,48 & 11,94 & - & $0,44 *$ & $0,29 *$ & $0,43^{*}$ & 0,78 & 13,38 \\
\hline
\end{tabular}

${ }^{n}$ Diferença não significativa entre as médias, pelo teste $\mathrm{F}$, na análise da variância, a $5 \%$ de probabilidade. *Diferença significativa em relação à testemunha (T), pelo teste de Dunnett, a 5\% de probabilidade. 

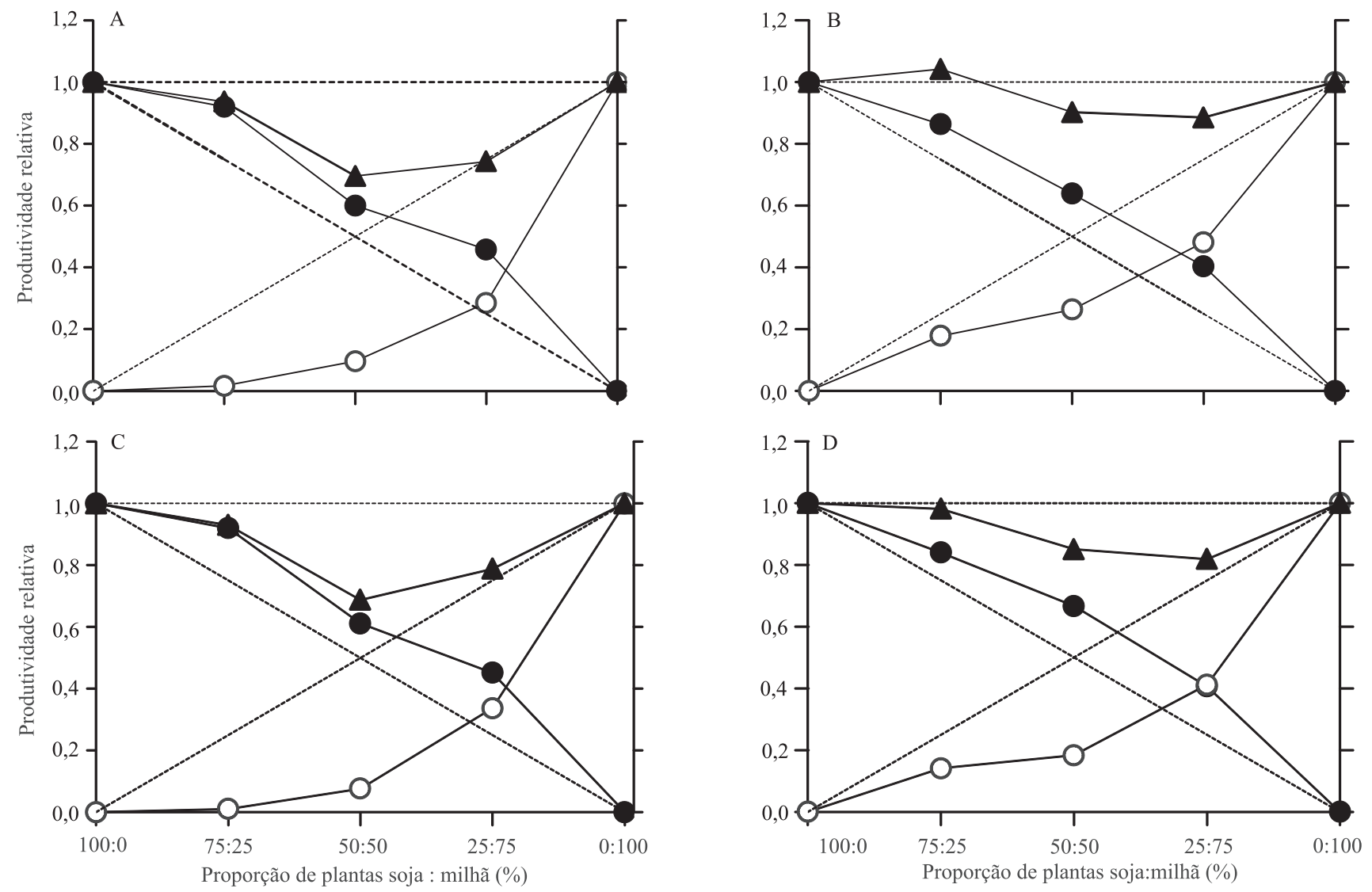

Figura 2. Produtividade relativa da soja $(\bullet)$ e da milhã (Digitaria ciliaris) $(\circ)$ e produtividade relativa total $(\boldsymbol{\nabla})$, quanto à área foliar (A e B, para 2009/2010 e 2010/2011, respectivamente) e matéria seca da parte aérea (C e D, para 2009/2010 e 2010/2011, respectivamente), em função das proporções entre as espécies. As linhas tracejadas referem-se às produtividades relativas hipotéticas (quando não ocorre interferência de uma espécie sobre a outra).

\section{Conclusões}

1. A competição entre milhã e arroz irrigado ou soja ocorre basicamente pelos mesmos recursos do ambiente.

2. Plantas de milhã apresentam menor habilidade competitiva por indivíduo do que as de arroz irrigado e soja, quando as culturas estão na mesma proporção de plantas.

3. Quando as culturas do arroz irrigado e soja estão associadas à milhã, a competição intraespecífica predomina, enquanto para a planta daninha prevalece a competição interespecífica.

\section{Referências}

AGOSTINETTO, D.; FLECK, N.G.; RIZZARDI, M.A.; BALBINOT JUNIOR, A.A. Perdas de rendimento de grãos na cultura de arroz irrigado em função da população de plantas e da época relativa de emergência de arroz-vermelho ou de seu genótipo simulador de infestação de arroz-vermelho. Planta Daninha, v.22, p.175-183, 2004. DOI: 10.1590/S0100-83582004000200002.

AGOSTINETTO, D.; GALON, L.; MORAES, P.V.D.; RIGOLI, R.P.; TIRONI, S.P.; PANOZZO, L.E. Competitividade relativa entre cultivares de arroz irrigado e biótipo de capim-arroz (Echinochoa spp.). Planta Daninha, v.26, p.757-766, 2008. DOI: 10.1590/S0100-83582008000400007.

AGOSTINETTO, D.; RIGOLI, R.P.; GALON, L.; MORAES, P.V.D. de; FONTANA, L.C. Competitividade relativa da soja em convivência com papuã (Brachiaria plantaginea). Scientia Agraria, v.10, p.185-190, 2009.

BIANCHI, M.A.; FLECK, N.G.; LAMEGO, F.P. Proporção entre plantas de soja e plantas competidoras e as relações de interferência mútua. Ciência Rural, v.36, p.1380-1387, 2006. DOI: 10.1590/ S0103-84782006000500006.

CARVALHO, S.J.P. de; CHRISTOFFOLETI, P.J. Competition of Amaranthus species with dry bean plants. Scientia Agricola, v.65, p.239-245, 2008. DOI: 10.1590/S0103-90162008000300003. 
CONGRESSO BRASILEIRO DE ARROZ IRRIGADO, 5.; REUNIÃO DA CULTURA DO ARROZ IRRIGADO, 27., 2007, Pelotas. Arroz irrigado: recomendações técnicas da pesquisa para o Sul do Brasil. Pelotas: Sosbai, 2007. 154p.

COUSENS, R. Aspects of the design and interpretation of competition (interference) experiments. Weed Technology, v.5, p.664-673, 1991.

COUSENS, R.; O'NEILL, M. Density dependence of replacement series experiments. Oikos, v.6, p.347-352, 1993. DOI: $10.2307 / 3544824$.

DAL MAGRO, T.; SCHAEDLER, C.E.; FONTANA, L.C.; AGOSTINETTO, D.; VARGAS, L. Habilidade competitiva entre biótipos de Cyperus difformis L. resistente ou suscetível a herbicidas inibidores de ALS e destes com arroz irrigado. Bragantia, v.70, p.294-301, 2011. DOI: 10.1590/S0006-87052011000200007.

FLECK, N.G.; AGOSTINETTO, D.; GALON, L.; SCHAEDLER, C.E. Competitividade relativa entre cultivares de arroz irrigado e biótipo de arroz-vermelho. Planta Daninha, v.26, p.101-111, 2008. DOI: 10.1590/S0100-83582008000100011.

FLECK, N.G.; BIANCHI, M.A.; RIZZARDI, M.A.; AGOSTINETTO, D. Interferência de Raphanus sativus sobre cultivares de soja durante a fase vegetativa de desenvolvimento da cultura. Planta Daninha, v.24, p.425-434, 2006. DOI: 10.1590/ S0100-83582006000300002.

GALON, L.; AGOSTINETTO, D.; MORAES, P.V.D.; TIRONI, S.P.; DAL MAGRO, T. Estimativa das perdas de produtividade de grãos em cultivares de arroz (Oryza sativa) pela interferência do capim-arroz (Echinochloa spp.). Planta Daninha, v.25, p.697-707, 2007. DOI: $10.1590 / \mathrm{S} 0100-83582007000400006$.

HOFFMAN, M.L.; BUHLER, D.D. Utilizing Sorghum as a functional model of crop-weed competition. I. Establishing a competitive hierarchy. Weed Science, v.50, p.466-472, 2002. DOI: 10.1614/0043-1745(2002)050[0466:USAAFM]2.0.CO;2.

JANNINK, J.L.; ORF, J.H.; JORDAN, N.R.; SHAW, R.G. Index selection for weed suppressive ability in soybean. Crop Science, v.40, p.1087-1094, 2000. DOI: 10.2135/cropsci2000.4041087x.

MUNENE, J.T.; KINYAMARIO, J.I.; HOLST, N.; MWORIA, J.K. Competition between cultivated rice (Oryza sativa) and wild rice (Oryza punctata) in Kenya. African Journal of Agricultural Research, v.3, p.605-611, 2008.

NEPOMUCENO, M.; ALVES, P.L.C.A.; DIAS, T.C.S.; PAVANI, M.C.M.D. Períodos de interferência das plantas daninhas na cultura da soja nos sistemas de semeadura direta e convencional. Planta Daninha, v.25, p.43-50, 2007. DOI: 10.1590/ S0100-83582007000100005.
PASSINI, T.; CHRISTOFFOLETI, P.J.; YADA, I.F.U. Competitivity of the common-bean plant relative to the weed alexandergrass [Brachiaria plantaginea (Link) Hitch.]. Scientia Agricola, v.60, p.259-268, 2003. DOI: 10.1590/ S0103-90162003000200009.

RADOSEVICH, R.S.; HOLT, J.S.; GHERSA, C. Ecology of weeds and invasive plants: relationship to agriculture and natural resource management. $3^{\text {rd }}$ ed. New York: Wiley, 2007. 589p. DOI: 10.1002/9780470168943.

RADOSEVICH, S.R. Methods to study interactions among crops and weeds. Weed Technology, v.1, p.190-198, 1987.

REUNIÃO DE PESQUISA DA SOJA DA REGIÃO SUL, 37. 2009, Porto Alegre. Indicações técnicas para a cultura de soja no Rio Grande do Sul e em Santa Catarina 2009/2010. Porto Alegre: Universidade Federal do Rio Grande do Sul, 2009. 144p.

RIGOLI, R.P.; AGOSTINETTO, D.; SCHAEDLER, C.E.; DAL MAGRO, T.; TIRONI, S.V. Habilidade competitiva relativa do trigo (Triticum aestivum) em convivência com azevém (Lolium multiflorum) ou nabo (Raphanus raphanistrum). Planta Daninha, v.26, p.93-100, 2008. DOI: 10.1590/S0100-83582008000100010.

RIZZARDI, M.A.; FLECK, N.G.; AGOSTINETTO, D. Nível de dano econômico como critério para controle de picão-preto em soja. Planta Daninha, v.21, p.273-282, 2003. DOI: 10.1590/ S0100-83582003000200013.

RIZZARDI, M.A.; ROMAN, E.S.; BOROWSKI, D.Z.; MARCON, R. Interferência de populações de Euphorbia heterophylla e Ipomoea ramosissima isoladas ou em misturas sobre a cultura de soja. Planta Daninha, v.22, p.29-34, 2004. DOI: 10.1590/ S0100-83582004000100004.

ROUSH, M.L.; RADOSEVICH, S.R.; WAGNER, R.G.; MAXWELL, B.C.; PETERSEN, T.D. A comparison of methods for measuring effects of density and proportion in plant competition experiments. Weed Science, v.37, p.268-275, 1989.

SCHAEDLER, C.E. Resistência de Fimbristylis miliacea (L.) Vahl aos herbicidas inibidores da enzima ALS. 2011. 117p. Tese (Doutorado) - Universidade Federal de Pelotas, Pelotas.

VILÁ, M.; WILLIAMSON, M.; LONSDALE, M. Competition experiments on alien weeds with crops: lessons for measuring plant invasion impact? Biological Invasions, v.6, p.59-69, 2004. DOI: 10.1023/B:BINV.0000010122.77024.8a.

WOLDEAMLAK, A.; BASTIAANS, L.; STRUIK, P.C. Competition and niche differentiation in barley (Hordeum vulgare) and wheat (Triticum aestivum) mixtures under rainfed conditions in the Central Highlands of Eritrea. Journal of Agricultural Science, v.49, p.95-112, 2001.

Recebido em 6 de maio de 2013 e aprovado em 27 de setembro de 2013

Pesq. agropec. bras., Brasília, v.48, n.10, p.1315-1322, out. 2013

DOI: $10.1590 / \mathrm{S} 0100-204 \mathrm{X} 2013001000002$ 